\title{
A comparison of phenytoin and pheneturide in patients with epilepsy: a double-blind cross-over trial
}

\author{
FB GIBBERD, DM PARK, G SCOTT, MJ GAWEL, DE FRY, NGR PAGE, C ENGLER, \\ JR ENGLISH, F CLIFFORD ROSE
}

\begin{abstract}
From the Departments of Neurology at Westminster, Charing Cross and Southend Hospitals, the West Park Laboratories Epsom and Syntex Pharmaceuticals Ltd.
\end{abstract}

SUMMARY A double-blind cross-over trial between pheneturide and phenytoin in ninety-four outpatients with epilepsy is described. There was no significant difference between the frequency of seizures in the two groups. The difficulties in comparing two anticonvulsants of similar efficacy are discussed particularly in relation to ethical problems, the selection of patients and trial design.

Recent research in anticonvulsant drugs has concentrated on their mode of action, their absorption, metabolism and elimination. Thus while the pharmacokinetics of these drugs are well understood, there are few adequate trials to test their efficacy in the management of epilepsy, ${ }^{12}$ possibly because ethical and design difficulties frequently occur. Ideally a drug should be tested against a placebo, because drug interactions may occur when the drug to be tested is added to an established anticonvulsant regime. However, ethical constraints prevent a simple trial of a drug against placebo in patients with a new diagnosis of epilepsy. Alternatively, a new drug may be compared with a well established drug, either between patients or on a "within-patient" basis sequentially in the same patients. A randomised cross-over trial partly alleviates the pharmacokinetic problems of carryover. In view of the need for optimum blood level ranges a further problem is introduced. Since these levels are used to adjust dosage, the trial cannot be double-blind without the help of a separate investigator using identical tablets of differing strengths. The frequency of seizures also varies considerably from patient to patient and from time to time in the same patient, and the trial therefore needs to be of adequate duration.

Address for reprint requests: Dr FB Gibberd, the Westminster Hospital, Dean Ryle St., London SWIP 2AP, UK.

Received 14 January 1982 and in revised form 14 July 1982. Accepted 9 August 1982
In this trial we have attempted to overcome some of these difficulties by adopting a randomised doubleblind cross-over design. Some flexibility of the drug dose was allowed for the control of seizures, although the investigator was unaware at any time of the serum drug level. The unwanted effects experienced and the number of days during which one or more seizures occurred (seizure days) were recorded. Because of this trial design serum drug levels had to be considered retrospectively.

\section{Subjects}

Any patient over the age of 15 years, newly referred and diagnosed as having epilepsy requiring anticonvulsant therapy was included. Patients who had received more than one type of anticonvulsant drug, or regular treatment for epilepsy prior to the convulsion which had led to their referral, were excluded. The trial was carried out over a five year period in the neurological out-patient clinics at the Westminster, Charing Cross and Southend groups of hospitals. The nature and aims of the trial were explained to the patients and their informed consent obtained. They were asked to record their seizures, to obtain all medication from the hospital and to bring their tablets with them on each visit to out-patients.

\section{Methods}

Each patient was allocated at random to a régime consisting in phase 1 of either pheneturide $200 \mathrm{mg}$ three times daily or phenytoin $100 \mathrm{mg}$ three times daily, given for about six months. In phase 2 the patient would cross over to the alternative drug for a similar length of time. Both drugs were presented as identical round white sugar coated tablets, dispensed from the hospital pharmacy. Other anticonvulsant drugs, barbiturates and folic acid were not 
allowed during the course of the trials. A number of patients had been recently started on anticonvulsants by the referring doctor. These patients were asked to make a gradual transfer to the trial medication.

The subjects were seen at two, four, twelve and twentyfour weeks after entry, although those with high seizure frequency could be seen more often at the discretion of the investigator. A separate record form was completed at each visit and not referred to at subsequent visits. The seizure frequency, recorded as "seizure-days,", was reckoned as the number of 24 hour periods in which one or more seizures occurred. For the purpose of the study an attack was defined as a seizure associated with unconsciousness. Focal attacks or alterations of awareness without unconsciousness were not considered to be seizures for the purpose of the record. Should the patient have had major seizures in any three or more 24 hour periods (not necessarily consecutive) the investigator could increase the dose to four tablets daily or switch to phase 2 early. The patients who switched early could be analysed, as a seizure frequency for them was obtained. In the results these patients are identifiable. By allowing early switching to phase 2 ethical problems of persisting with ineffective treatment were avoided. The cross-over was made gradually over a two week period for a three times daily regime and over three weeks for a four times daily regime. The presence of drowsiness, depression, ataxia, nystagmus and gum hypertrophy were specifically recorded on a scale of 0 (none) to 3 (severe). Other unwanted effects were elicited by indirect questioning. In addition to early transfer from phase 1 to phase 2 or withdrawal from the trial because of inadequate control, transfer or withdrawal could also be implemented because of unwanted effects of the drugs. A tablet count, as a check of compliance, was performed at each visit.

Blood samples for measurement of haemoglobin, serum calcium, alkaline phosphatase, folate and vitamin B.12, plasma gamma glutamyl transpeptidase and drug concentrations were taken at each visit. Drug assays were by gas-liquid chromatography, after extraction from the acidified plasma into ethyl-acetate and concentration. ${ }^{3}$

\section{Results}

Ninety-four patients of whom 44 were male and 50 female entered the trial. The majority were aged between 20 and 35 years (range 16-65). The types of seizure disturbances encountered are shown in table 1. Before entry to the trial, seizures had usually occurred for less than two years (table 2). Thirty-eight patients were receiving a single anticonvulsant prescribed by the referring doctor just prior to commencing the trial and this medication was switched to the trial therapy. The diagram shows the flow of patients through the trial. Of the 94 patients who entered the trial, 51 completed six months (minimum 5 maximum 9 months) in phase 1 (22 on pheneturide and 29 on phenytoin). Fourteen completed more than two weeks but less than six months and therefore switched early to the alternate therapy. Twenty-nine patients were withdrawn, of
Table 1

\begin{tabular}{lc}
\hline $\begin{array}{l}\text { Type of seizure disorder } \\
\text { prior to admission to the study }\end{array}$ & Number of patients \\
\hline Generalised seizures & 55 \\
Focal (partial) only & 2 \\
Complex partial seizures only & 16 \\
Unspecified major and minor & 9 \\
Unspecified & 12 \\
Total & 94
\end{tabular}

Table 2 Time elapsed between 1st seizure and entry to the trial

\begin{tabular}{lc}
\hline & $\begin{array}{l}\text { No of } \\
\text { patients }\end{array}$ \\
\hline Less than one year & 40 \\
$1-2$ year & 13 \\
3-4 years & 6 \\
Greater than four years & 21 \\
Unspecified & 14 \\
Total & 94 \\
\hline
\end{tabular}

whom 18 were lost to follow-up, three were unable to complete 2 weeks on the drug because of very frequent seizures and eight had unacceptable sideeffects within two weeks. Therefore 65 entered phase 2 and 54 completed the full trial.

The full results for the major seizures are shown in tables 3 and 4 . The flow diagram (figure) shows how the numbers of each category were obtained. Table 5 gives the results for the number of seizures and the number of days observed for all the patients who entered the study. Although there was a slightly higher seizure frequency on pheneturide compared with phenytoin the patients' progress through the trial was not comparable, because some patients did

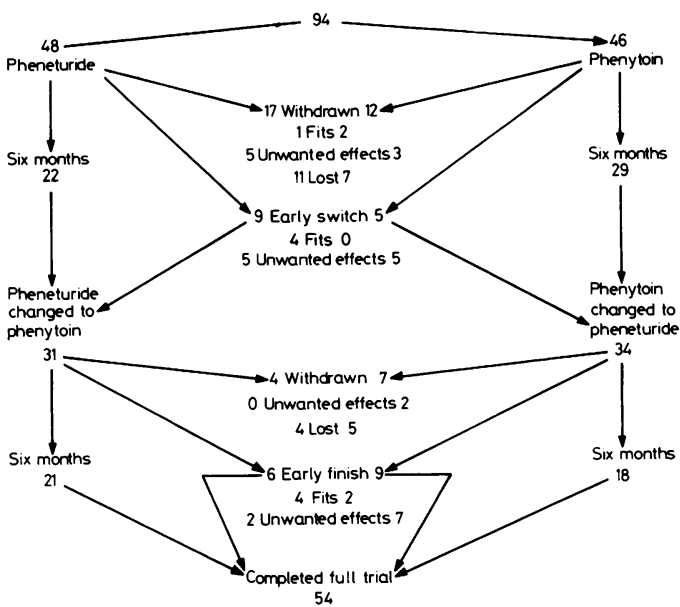

Figure (Arabic numerals refer to the number of patients). 
Table 3 Patients who received pheneturide first

芌

On pheneturide (Phase I)

Completed full six months

Withudrawn

Switched early because of seizures or unwanted effects

On Phenytoin (Phase II)

Completed full six months

Withdrawn

Switched early because of seizures or unwanted effects

$\begin{array}{rr}22 & 195 \\ 17 & 137 \\ 5 & \end{array}$

$\begin{array}{rr}195 & 8 \cdot 7 \\ 43 & 2 \cdot 5 \\ 137 & 34.2 \\ 3 & 0.6\end{array}$

$24 \cdot 4$
$6 \cdot()$
$30 \cdot 9$
$1 \cdot 2$

3912
573
354
237

178
$33 \cdot 7$
$88 \cdot 5$
$47 \cdot 4$

\section{9}

$0 \cdot(04985$
$0 \cdot(075(4)$

(). 38701

(). ()1266

$\begin{array}{rrrrrrrl}21 & 130 & 6 \cdot 5 & 18 \cdot 3 & 4082 & 194 & 43 & 0 \cdot 03185 \\ 4 & 0 & 0 & 0 & 129 & 32 \cdot 3 & 48 & 0 \\ 4 & 84 & 21 & 17 \cdot 4 & 360 & 90 & 42 \cdot 3 & 0 \cdot 23 \\ 2 & 0 & 0 & 0 & 150 & 75 & 37 & 0\end{array}$

Table 4 Patients who received phenvtoin first

咅

On phenytoin (Phase I)

Completed full six months

Withdrawn

Switched early because of seizures

On Pheneturide (Phase II)

Completed full six months

Withdrawn

Switched early because of seizures

or unwanted effects

$\begin{array}{rr}29 & 155 \\ 12 & 5 \\ 5 & 9\end{array}$

\section{$5 \cdot 3$}

(). 4

\section{$14 \cdot 25$}

$0 \cdot 8$
$2 \cdot 2$

183
1
25
0

$10 \cdot 2$
$0 \cdot 1$
$12 \cdot 5$
0
$3(0 \cdot 1$
$0 \cdot 4$
$7 \cdot 5$
0

0

5158
546
293

3094
456
172
354

354

$\begin{array}{ll}178 & 46 \\ 45 \cdot 5 & 47 \cdot 8 \\ 58 \cdot 5 & 39 \\ & \\ 172 & 41 \\ 91 \cdot 2 & 10 \\ 86 & 1 \\ 39 \cdot 3 & 41\end{array}$

$39 \cdot 3$
Number of

days observed

days in which

seizures occurred

\section{Drug pheneturide}

Six months

Early finish

Total

$\begin{array}{lr}40 & 378 \\ 18 & 165 \\ 58 & 543 \\ & \\ 50 & 285 \\ 11 & 93 \\ 61 & 378\end{array}$

Drug phenyt

Early finish

Total

378
165
543
285
93
378

$\begin{array}{rr}70 \times 6 & 5 \cdot 4 \\ 1117 & 14 \cdot 8 \\ 8123 & 6 \cdot 7 \\ & \\ 9240 & 3 \cdot 1 \\ 803 & 11 \cdot 6 \\ 10043 & 3 \cdot 8\end{array}$

Seizure frequency = seizures $/ 100$ days 
not cross over to the second drug. Analysis was performed on the results of the 54 patients who took both drugs according to the protocol (table 6). This was made up of two groups, one in which a full six months on both phenytoin and pheneturide were completed and the other where either phase 1 or phase 2 or both terminated early. This latter group could be further divided into those who finished early because of seizures or unwanted effects. The results show no statistical difference between the seizure frequencies while on pheneturide or phenytoin (Wilcoxon Ranked Paired and McNemar tests).

Those withdrawn because of unwanted effects had about one-tenth the seizure frequency of those completing six months on the drug, although the difference was not statistically significant $(p=0 \cdot 28)$ with this small number of patients.

Fit frequency in those withdrawing because of fits was also clearly greater than the frequency in those withdrawing because of unwanted effects. This suggests either that unwanted effects were less acceptable to those with few seizures or that when anticonvulsants were effective unwanted effects were worse. However, only one patient withdrawn from the trial because of unwanted effects had a higher blood concentration of anticonvulsant drug than recommended.

\section{UNWANTED EFFECTS}

Drowsiness and depression were the commonest sideeffects. Ataxia, nystamus and gum hypertrophy were rarely seen. Other unwanted effects, multiple or single, were reported by 41 patients receiving pheneturide and 37 receiving phenytoin. Skin disorders, including rashes were seen in nine patients on pheneturide and by 11 on phenytoin. Similarly headache was reported with both drugs (eight and nine patients respectively), and dizziness or vertigo was mentioned by 10 and four patients respectively. Side-effects were troublesome enough to result in withdrawing the drug or switching early in 19 patients receiving pheneturide and in 10 of those receiving phenytoin. This suggests that while side-effects were as frequent with either drug they were more likely to lead to withdrawal of pheneturide. About half the patients who crossed over early from phase 1 to phase 2 also withdrew early from phase 2 of the trial and gave the same reasons for doing so.

\section{LABORATORY RESULTS}

Blood samples were not always received for each of the visits and as a consequence, interpretation of these results was difficult. Both drugs caused increases in plasma gamma glutamyl transpeptidase. The plasma folic acid levels tended to decrease and this was most marked at the third month in patients starting on pheneturide and after the first month of transferring to it. Serum B12 levels showed both increases and decreases from admission values. There were no significant changes in the results for haemoglobin, alkaline phosphatase and calcium.

Seventy-three per cent of patients had plasma levels of pheneturide within the recommended range of $50-80 \mu \mathrm{mol} / \mathrm{l}$ (manufacturer's data) but $60 \%$ of the patients had levels for serum phenytoin of less than 40 $\mu \mathrm{mol} / \mathrm{l}$. In patients withdrawn or transferred early because of side-effects, only one on phenytoin had a blood level above the therapeutic range. It was disturbing to note that in five patients in Group 1 and six in Group 2, the presence of the drug could not be detected on at least one occasion. In addition, in spite of the protocol, the presence of other anticonvulsants was detected on occasion in six patients.

\section{Discussion}

Pheneturide is an anticonvulsant structurally related to the barbiturates and to primidone. Since its introduction there have been very few trials to study its therapeutic value and none where pheneturide was

Table 6 Fit frequency for the 54 patients who completed the full trial according to the protocol

\begin{tabular}{|c|c|c|c|c|c|c|c|c|}
\hline & \multicolumn{4}{|l|}{ Pheneturide } & \multicolumn{4}{|l|}{ Phenytoin } \\
\hline & $\begin{array}{l}\text { Number of } \\
\text { patients }\end{array}$ & $\begin{array}{l}\text { Number of } \\
\text { days in which } \\
\text { seizures } \\
\text { occurred }\end{array}$ & $\begin{array}{l}\text { Number of } \\
\text { days } \\
\text { observed }\end{array}$ & $\begin{array}{l}\text { Seizure } \\
\text { frequency } \\
\text { per } 100 \\
\text { days }\end{array}$ & $\begin{array}{l}\text { Number of } \\
\text { days in which } \\
\text { seizures } \\
\text { occurred }\end{array}$ & $\begin{array}{l}\text { Number of } \\
\text { days } \\
\text { observed }\end{array}$ & $\begin{array}{l}\text { Seizure } \\
\text { frequency } \\
\text { per } 100 \\
\text { days }\end{array}$ & $\begin{array}{l}\text { Significance } \\
\text { of difference } \\
\text { in seizure } \\
\text { frequency }\end{array}$ \\
\hline $\begin{array}{l}\text { Completed six months } \\
\text { in both phases }\end{array}$ & 33 & 365 & 5700 & $6 \cdot 4$ & 274 & 5500 & $5 \cdot 0$ & $\begin{array}{r}>>0.05^{*} \\
0.66 \dagger\end{array}$ \\
\hline
\end{tabular}

*Wilcoxon Ranked Pair Test.

$\dagger$ McNemar Test. 
given alone. Taen et $\mathrm{ll}^{4}$ thought it had a beneficial effect when added to medication for temporal lobe epilepsy. Bowe and Shersby 5 also thought it had a beneficial effect when added to the therapy of children in an institution for epilepsy. Similarly Vas and Parsonage ${ }^{6}$ reported the effects of adding pheneturide to current medication with useful results in one-third but another third of the patients were unable to tolerate the drug because of side-effects. Hershon and Parsonage ${ }^{7}$ reported a double blind trial adding either pheneturide or diazepam to current medication. The consequent reduction in seizures was similar for both drugs. The results of the present trial indicate that the anticonvulsant potential of pheneturide is similar to that of phenytoin, and that there is a similar frequency of side-effects for both drugs. Since the trial was carried out, new EEC regulations on data requirements for anti-epileptic drugs have been published. These far exceeded the data available on pheneturide and this has led to the withdrawal of the drug from the market. Nevertheless, this trial has presented an opportunity to study problems inherent in the assessment of a new anticonvulsant. The trial involved out-patients, most of whom were new referrals, rather than patients in institutions and in many respects they were similar to the majority of sufferers from epilepsy.

Sixty per cent of all estimations for serum phenytoin during this trial were below the therapeutic range, indicating that a standardised dose does not allow for individual drug metabolism and compliance. In contrast the standardised dose of pheneturide gave a plasma level of between 50 and 80 $\mu \mathrm{mol} / \mathrm{l}$ in $73 \%$ of patients suggesting less variation in individual metabolism of this drug.

The trial has illustrated difficulties that are common enough in the management of epilepsy, including individual reactions to drugs, varying compliance not only by the patient but also by the physician. Because most of our patients remained in good health despite epilepsy and continued at work, they were intolerant of unwanted effects and this is probably the principal reason for poor compliance in this study. Although three hospital groups cooperated, it took five years to find 94 new patients with epilepsy who could meet the criteria for entry to this trial. The total duration of the trial for each patient was twelve months, with up to six months on each drug and it is likely that even over this period, considerable variation of individual seizure frequency would have occurred. Had the protocol required the investigators to establish and maintain commonly acceptable serum therapeutic levels for the drugs, the time for each patient in each stage would have necessarily increased. Furthermore, the seizure experience of patients suitable for a trial with one drug may be so low that even a six month period is insufficient for comparison purposes.

From an ethical point of view it may be considered unacceptable for an anticonvulsant to be tested against a placebo, particularly if a degree of activity of a drug has already been established. Ethical considerations played an important part in the design of this protocol, allowing early withdrawals or crossovers. There was no clear evidence that either drug was so ineffective as to be ethically unacceptable as a first line drug but it could be argued that for some patients a placebo might have been just as effective as the anticonvulsant and would have given fewer unwanted effects. The design employed in this trial is not able to answer this point.

In view of the reported side-effects with pheneturide, ${ }^{6}$ it was surprising to find that the frequency of side-effects was similar for phenytoin. Furthermore, the doses selected for the trial generally resulted in sub-therapeutic serum levels for phenytoin and relatively higher levels for pheneturide. Those withdrawn for unwanted effects had a lower seizure frequency than those completing a period on the drug which suggests that the therapeutic and toxic doses of the drugs were similar.

There are difficulties in the analysis of results in any trial of anticonvulsants. Many of these difficulties were analysed in a recent international symposium. ${ }^{8}$ Either the total numbers of seizures occurring on the drugs or, as in this study, the frequencies of the seizures while on the drugs may be compared. Some system for weighting the severity of seizures could have been employed but any seizure represents a failure of therapy. The use of the "seizure day" as a unit of measurement did not remove the need to depend upon the patient's own records, but it did simplify his record keeping. Early withdrawal or cross-over presents a further difficulty in analysis. A patient's experience with the drug, however short, should not be lost to the overall results, and we therefore calculated seizure frequency over short periods so that all the results of all the patients participating could be used. The design of this trial has avoided the problems of drug interactions, and would be appropriate with minor modifications for further trials of anticonvulsant drugs in out-patients.

We thank Mr D Timlin for help with the statistics.

\section{References}

' Coatsworth JJ. Penry JK. General principles, clinical efficacy and use. In: Woodbury DM, Penry JK. Schmidt RP. eds. Antiepileptic Drugs. New York: Raven Press, 1972:92.

- Richens A. Drug Treatment of Epilepsy. London: Henry Kimptom, 1976:15+171. 
${ }^{3}$ Papadopoulos AS, Baylis EM, Fry DE, Marks V. A rapid micromethod for determining four anticonvulsant drugs by gasliquid chromoatography. Clin Chim Acta 1973;48:135-41.

${ }^{4}$ Taen S, Goto Y, Tokuda Y, Arai S, Sekiba K, Marita S. The experience with the anti-epilepticum "Pheneturide". No To Shinkei 1961;13:71-5.

${ }^{5}$ Bowe JC, Shersby BJ. Pheneturide in epilepsy preliminary communication. Br J Clin Pract 1973;27:174-6.
${ }^{6}$ Vas CJ, Parsonage MJ. Treatment of intractable temporal lobe epilepsy with pheneturide. Acta Neurol Scand 1967;43:580-6.

' Hershon HI, Parsonage M. Comparative trial of diazepam and pheneturide in treatment of epilepsy. Lancet 1969;ii:859-62.

${ }^{8}$ Dom M, Grom L, Penry JK, eds. Advances in epileptology. The XIIth Epilepsy International Symposium Controlled Trials. New York: Raven Press, 1981:97-165. 